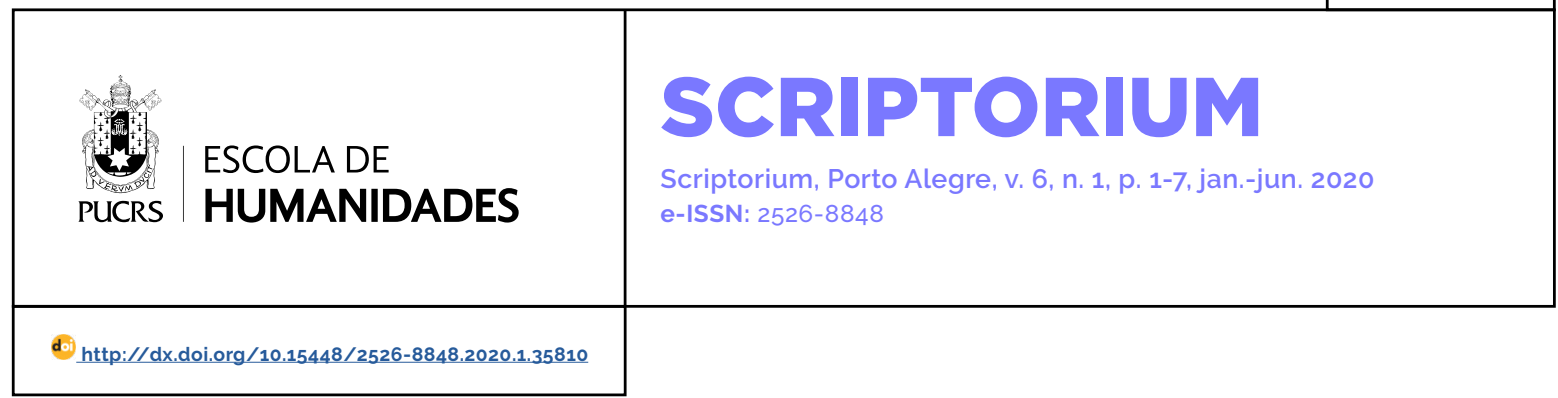

TEMATHIS

\title{
O tempo e a música: uma proposta de abordagem da obra Quatro Quartetos, de T.S. Eliot
}

Time and music: an alternative approach of the work Four Quartets, by T. S. Eliot

\author{
João Felipe Gremski ${ }^{1}$ \\ orcid.org/0000-0001-7139-8579 \\ gremski@msn.com
}

Recebido em: 27 set. 2019

Aceito em: 10 jan. 2020.

Publicado em: 20 jul. 2020.

\begin{abstract}
Resumo: O presente artigo tem como objetivo propor uma análise da obra Quatro Quartetos, do americano T. S. Eliot, a partir de um viés alternativo: a teoria da relatividade de Albert Einstein e a música, tendo como elemento unificador a questão do tempo. Se Einstein mudou os paradigmas da física ao propor que o tempo é uma grandeza relativa, e não absoluta, o axioma de um tempo estritamente linear, presente-passado-futuro, deixou de ser ponto passivo no mundo científico e a noção de 'viagem no tempo' passou a ser uma possibilidade. O presente artigo estabelece uma ponte entre tal raciocínio e o poema Quatro Quartetos a partir da noção de eterno tempo presente, tão cara à voz enunciadora do poema, demonstrando que tal ideal pode ser alcançado pela palavra poética através de um estado de sinergia entre os tempos passado, presente e futuro.

Palavras-chave: T. S. Eliot; música; tempo.
\end{abstract}

Abstract: The article suggests an analysis of T. S. Eliot's Four Quartets from an alternative approach: Albert Einstein's theory of relativity and music, having as a unifying element the notion of time. Einstein changed physics' paradigms by proposing that time is relative, and not absolute, as it was a common belief. By doing that, the axiom of time as a linear thing was put into perspective in the scientific world, and the idea of travelling through time is, at least theoretically, considered a possibility. Thus, this article tries to establish a bridge between this line of thought and the poem Four Quartets by recurring to the idea that 'all time is eternally present', a theme that appears throughout the whole poem, showing that this ideal can be reached using the poetic word and, by consequence, the poetic persona can establish a synergy between past, present and future.

Keywords: T. S. Eliot; music; time.

\section{Introdução}

A obra Quatro Quartetos, publicada por T. S. Eliot em 1943 (em meio à $2^{a}$ Guerra Mundial), trabalha principalmente com a relação vida e tempo, ou melhor, a vida no tempo. Ela propõe um estado em que tanto passado e futuro são, na verdade, parte de um tempo presente, este eterno e, portanto, inapreensivel dentro da escala temporal a que estamos acostumados a considerar.

Terry Fairchild, no artigo "Time, Eternity, and Immortality in T. S. Eliot's Four Quartets" (1999) complementa essa ideia, presente já nos primeiros versos do poema, como um elemento vital dos Quatro Quartetos: "eternity can and must be incorporated into the life of time as the sole means to revitalize the spiritual wasteland of modern life. Read with greatest profundity, the Four Quartets present the triumph of life over time" (FAIRCHILD, 1999, p. 53)². 
Fazendo um paralelo com Terra Devastada, livro publicado em 1922, Fairchild (p. 53) aponta para uma redenção através do triunfo da vida sobre o tempo, colocando inclusive uma equação para esse raciocínio: Time + eternity = entirety $($ Tempo + Eternidade = totalidade $)$. Aquela cidade irreal de antes, em que "Sob a névoa marrom de uma aurora de inverno, / Multidões afluiram à ponte de Londres, tantos, não sabia que a morte desfizera tantos" (ELIOT, 2018, p. 117), agora, nos Quartetos, tem a chance de encontrar uma forma de revitalizar a terra devastada da vida moderna:

Os tempos passado e futuro

Estão talvez no tempo futuro,

E o futuro, contido no tempo passado.

Se todo o tempo é presente eternamente

O tempo todo é irredimivel (ELIOT, 2018, p. 225).

A localização, ou melhor, o eterno momento em que esse encontro acontece Eliot chama, algumas estrofes depois, de "ponto imóvel do mundo que gira" (2018, p. 229). Nele, não há ida nem vinda, nem suspensão nem movimento, mas é o local em que "passado e futuro se juntam", onde a dança acontece - ou, para nos aproveitarmos das metáforas que Eliot usa - onde a dança é. E é através da leitura e interpretação dos textos da literatura Védica, Bhagavat Gita e Upanixade que Eliot baseia a sua filosofia nos Quartetos.

Mas, não cabe aqui desenvolver um estudo dos Quartetos em relação às filosofias orientais. O importante é saber que Eliot propõe, na primeira parte do poema, uma vida dentro e fora do tempo (Burnt Norton); na segunda parte materializa essa representação (East Coker); na terceira (The Dry Salvages) o fluxo da vida é metaforizado como um correr de águas; e na última parte (Little Gidding) temos o ápice da espiritualidade através do fogo da purificação.

Tendo feito esse breve resumo, é importante analisarmos os Quartetos através de duas perspectivas que de início podem parecer diferentes, mas que, no poema de Eliot, se complementam: física e música. Física pensada aqui a partir das noções espaço-tempo de Einstein e eterno tempo presente de Eliot, e música na maneira com que o poeta americano trabalha a ideia de "música inaudita" nos Quatro Quartetos.

\section{Tempo é Relativo}

Antes de Einstein, a física Newtoniana considerava o tempo uma grandeza absoluta e o espaço uma grandeza relativa. Esta visão foi derrubada a partir da publicação da teoria da relatividade de Einstein, em 1905. Estudos teóricos do físico alemão passaram a considerar o tempo relativo; ou seja, conceitos temporais poderiam ser aplicados ao tempo assim como eram ao de espaço. O espaço-tempo passou a ser uma entidade geométrica unificada.

A velocidade, segundo Einstein, poderia afetar a ordenação dos eventos, principalmente no que se refere à luz. Se partirmos do pressuposto de que um observador e um objeto estão em diferentes pontos do espaço, digamos, a 100 anos-luz um do outro, a percepção que o observador terá do objeto será afetada pela velocidade da luz e a distância entre ele e o objeto. No caso, graças ao tempo com que a luz viaja pelo espaço, o observador verá o outro ponto já cem anos no passado, passado que, para o observador, é presente. E se nos utilizarmos da lógica do raciocínio de Einstein, o objeto em questão, no seu espaço específico, já está no futuro em relação ao observador.

Em outras palavras, um mesmo evento não pode ser considerado como um fenômeno isolado - acontecendo apenas uma única vez no tempo. Ele poderia existir, simultaneamente, no passado, presente e futuro. A famosa frase de Stephen Hawking resume bem essa ideia:

The light that we see from distant galaxies left
them millions of years ago, and in the case of
the most distant object that we have seen, the
light left some eight thousand million years
ago. Thus, when we look at the universe, we
are seeing it as it was in the past (HAWKING
apud FAIRCHILD, 1988, p. 28). ${ }^{32}$

O já citado Terry Fairchild, ao lembrar da mesma sentença, faz a seguinte colocação:

\footnotetext{
3 "A luz que vemos de galáxias distantes tem milhões de anos de idade, e no caso do objeto mais distante que vemos, a luz emitida tem mais ou menos oito milhões de anos. Assim, quando olhamos para o universo, olhamos para passado"
} 
What Hawking's example demonstrates is that time exists only in relationship to consciousness. Time cannot be said to exist until someone witnesses it or feels its effects. To the observer on earth, however, the event seems to be happening as it is being seen (FAIRCHILD, 1999, p. 89). ${ }^{43}$

Nesse sentido, é importante recorrermos a um trecho dos Quartetos, em "Burnt Norton", em que o autor trabalha justamente com esse raciocínio:

Os tempos passado e futuro

Permitem limitada consciência.

Ter consciência é não estar no tempo

Mas só no tempo podem o momento no jardim de rosas,

O momento na pérgula batida de chuva,

O momento na igreja fria, na noite plena,

Ser lembrados; enleados em passado e futuro.

Só pelo tempo tempo é conquistado. (ELIOT, 2018, p. 231)

Estar consciente é estar limitado ao passado e ao futuro, e apenas o tempo presente é ilimitado. Mas nós precisamos começar com o temporal - tempo passado e tempo futuro - para percebermos a sua dependência com o atemporal, o ponto imóvel onde há sempre dança, "enleada em passado e futuro". É apenas pelo tempo que podemos trazer nossas lembranças e recuperar e conquistar esse tempo.

Em um outro trecho dos Quartetos, agora em "The Dry Salvages", Eliot trabalha mais essa ideia:

Vocês não são as pessoas que sairam daquela estação

Ou as que vão chegar a algum terminal,

Enquanto os trilhos que se estreitam escorregam atrás de vocês;

E no convés do navio de carreira

Olhando o sulco que se alarga atrás de vocês, Vocês não vão pensar "o passado se encerrou" Ou "o futuro está à nossa frente" (ELIOT, 2018, p. 267).
É como se tudo estivesse acontecendo ao mesmo tempo - o eterno presente - e nós não pudéssemos nem ser aqueles que fomos no passado e nem aqueles que irão chegar na estação, no futuro. A linha de água que se forma atrás do barco em movimento não é o passado e muito menos um passado acabado; o destino final do navio não está no futuro: ele já é o presente. Presente passado e futuro são apenas um.

A "dança do ponto imóvel do mundo que gira" não é localizável no tempo, e é na mesma seção do trecho citado acima, "Dry Salvages" (p. 267), que fica (ainda) mais clara a influência da filosofia oriental nos Quartetos, especialmente o Bhagavad-Gita:

Às vezes penso se foi isso que Krishna quis dizer Entre outras coisas - ou um jeito de dizer a mesma coisa:

Que o futuro é canção apagada, uma rosa real ou ramo de lavanda

De triste arrependimento por quem não está aqui para se arrepender

Prensada entre páginas velhas de um livro que jamais foi aberto.

E o caminho que sobe é o que desce, a via que é a volta.

Nesse mundo em constante mudança, o tempo não pode ser apreendido. E, sobre essa passagem, Terry Fairchild menciona o quanto o tempo escorrega constantemente de nossas mãos e se torna algo diferente:

[...] the future into the present, the present into the past, the past into the remote past, and the remote past into forgetfulness. In this transitory world, the demise of an event exists before it has occurred, has "faded" before it was conceived, turned into a remembrance before it has happened (FAIRCHILD, 1999, p. 75).54

Para escaparmos da natureza destrutiva do tempo, Eliot sugere, ao longo dos Quartetos, que nós tentemos, através da história, filosofia e religião, transcender essa natureza, "o ponto de insatisfação", como ele nos diz na parte III de "Burnt Norton" (ELIOT, p. 231).

\footnotetext{
4 "O que o exemplo de Hawking demonstra é que o tempo existe apenas em relação à nossa consciência. O tempo só existe quando alguém está presente testemunhando ou sentindo seus efeitos. Para o observador na terra, o evento está acontecendo no momento que está sendo visto".

5 "[...] o futuro dentro do presente, o presente dentro do passado, o passado dentro de um passado remoto, e o passado remoto dentro do esquecimento. Nesse mundo transitório, o final de um evento acontece antes que ele tenha existido, apagou antes que pudesse ter sido concebido, virou uma lembrança antes de ter acontecido."
} 
E para voltarmos à física e à teoria da relatividade Einsteiniana, podemos ligar esse estado defendido pelo poeta como uma possibilidade plausivel, visto que o tempo, segundo a teoria de Einstein, é relativo, e não absoluto. O fato do tempo deixar de ser um ponto que caminha em uma única direção faz com que a noção Eliotiana de um círculo que gira em um ponto imóvel, onde passado e futuro se unem e dançam em um eterno presente, ganhe um sustentáculo interessante de discussão.

Se tudo é relativo quando falamos do tempo, por que não podemos manipulá-lo no sentido de transcendermos o indivíduo e nos comunicarmos com o universal? Eliot nos alerta disso na epígrafe de Heráclito, que abre os Quartetos: "embora a razão seja comum a todos, a maioria vive como se tivesse sabedoria própria" (2018, p. 223). ${ }^{65}$ É a proposta de sairmos do temporal individual para atingirmos o atemporal universal.

O final de "The Dry Salvages" segue trabalhando tais ideias, mas agora ele passa para uma discussão mais próxima do ponto que aspira chegar, ou ao menos obter um lampejo: amor, ardor, renúncia e entrega são palavras que ele traz aos versos para descrever esse "momento dentro e fora do tempo":

\section{[...] Mas apreender}

O ponto de intersecção do atemporal Com o tempo é ocupação para o santo E nem ocupação, mas algo dado

E recebido, morrendo-se uma vida em amor, Ardor e renúncia a si e entrega de si.

Para quase todos nós, resta só o inesperado Momento, momento dentro e fora do tempo, [...] (ELIOT, 2018, p. 273)

O restante do poema reúne a diversidade na unidade. Como nos diz Fairchild: "Once more Eliot calls for modesty, precision, and flexibility to pro- duce in poetry a 'complete consort,' just as fire and water will produce from death an eternal rebirth, and out of the incidents of history comes 'a pattern of timeless moments'" (FAIRCHILD, 1999, p. 85)76.

E é na figura da rosa e do fogo que o poema busca essa unidade:

Tudo quanto seja estará bem
Quando as línguas de chama se enveloparem
Para o coroado nó do fogo
E o fogo e a rosa forem um. (ELIOT, 2018, p. 295)

A rosa da perfeição e o fogo da destruição, como diz Fairchild. O teórico cita aqui Maharishi Mahesh, guru indiano, que chama essa aparente oposição (mas, na verdade, dualidade) entre a rosa e o fogo de "forças opositores no campo de batalha da vida" (MAHESH apud FAIRCHILD, 1999, p. 91). O momento dentro e fora do tempo, o eterno tempo presente de T.S. Eliot - aquele que a ciência moderna hoje discute como possibilidade real, graças à teoria da relatividade de Einstein.

\section{O Eterno Presente da Música nos Quartetos}

Os Quartetos de Eliot são comparados pela crítica com os últimos quartetos de Beethoven, notadamente os quartetos Op. 130, Op. 131 e Op. 132. E, de fato, há trabalhos muito interessantes em que é demonstrada a influência que eles tiveram na poesia de Eliot, e o quanto cada uma das quatro seções do poema se assemelham à estrutura dos quartetos finais de Beethoven ${ }^{87}$. Mas é preciso nos determos aqui em alguns momentos dos Quartetos em que a música aparece correlacionada à noção de tempo como um eterno presente.

Começando pela já mencionada epigrafe de Heráclito, Fairchild faz um paralelo com a música, argumentando o quanto a inscrição se assemelha a uma armadura de clave, estabelecendo, portanto,

\footnotetext{
6 A epígrafe, na abertura dos Quartetos, encontra-se em grego, e foi utilizada aqui a tradução presente nas notas referentes ao poema (ELIOT, 2018, p. 381)

7 "Mais uma vez Eliot pede por modéstia, precisão e flexibilidade para produzir, em poesia, uma harmonia completa; assim como fogo e água irão produzir, da morte, um eterno renascimento, e além dos incidentes da história vem um 'padrão de momentos sem fim."

8 Chamo a atenção para esses dois trabalhos: 1) Rees, T. (1969). The Orchestration of Meaning in T. S. Eliot's Four Quartets. The Journal of Aesthetics and Art Criticism, 28(1), 63-69. doi:10.2307/428910.

2) Nicolosi, R. (1980). T. S. Eliot and Music: An Introduction. The Musical Quarterly, 66(2), 192-204. Disponivel em: http://www.jstor.org/ stable/742087
} 
o tom da obra a ser tocada - ou, no caso de Eliot, lida - e os temas a serem desenvolvidos. O autor, inclusive, comenta que ela pertenceria originalmente apenas a "Burnt Norton", mas que, por apresentar um tema em comum a todo o poema, Eliot aplicou a todos os "movimentos" dos Quartetos.

A música representaria, nos momentos em que é citada direta e indiretamente, um estado a que nós devemos aspirar dentro dessa busca pelo eterno; a sua capacidade de dizer o indizivel e provocar um efeito na nossa natureza mais interior, como diz Schopenhauer:

It is such a great and exceedingly fine art, its effect on man's innermost nature is so powerful, and it is so completely and profoundly understood by him in his innermost being as an entirely universal language, whose distinctness surpasses even that of the world of perception itself [...]. We must attribute to music a far more serious and profound significance that refers to the innermost being of the world and of our own self (SCHOPENHAUER, 1966, p. 256). ${ }^{98}$

Tendo essa percepção em mente, e passando agora para os Quartetos, o primeiro "aparecimento" da música no poema é quando ela está "inaudita" no jardim de rosas, em "Burnt Norton": "E a ave chamou, em resposta à / Música inaudita no arbusto, / E o feixe invisivel dos olhos cruzou-se, pois as rosas / A olhos vistos pareceram flores vistas" (ELIOT, 2018, p. 227). O trecho alude ao poema "Ode a Uma Urna Grega", de John Keats:

É doce a melodia que se escuta; mais ainda,

Aquela que não se ouve; soai pois, o brandas flautas:

Não para o ouvido material, porém mais gratas

Tocai-nos para o espírito árias insonoras (KEATS, 2010, p. 47).

A música inaudita é superior à ouvida, não apenas por ser mais doce, mas porque está congelada no tempo. Ela é eterna, sem começo nem meio nem fim. Talvez seja mais doce justamente por apresentar o caráter eterno, ou porque vive completamente dentro da nossa imaginação e pode, portanto, transcender o mundo físico.
Essa música inaudita soa nesse jardim Eliotiano, fazendo com que as rosas - simbolo principal desse jardim - "a olhos vistos pareceram flores vistas". Como argumenta o crítico Harvey Gross, no artigo "Music and the analogue of feeling: notes on Eliot and Beethoven", há um reconhecimento universal de um ou mais sentimentos, seja quais forem eles (GROSS, 1959 p. 281).

Mais adiante, a dança no ponto imóvel do mundo que gira pressupõe que haja uma música tocando - uma música inaudita - nesse ponto imóvel. Ela seria essa música perfeita e infinita, "cercada entanto / Por uma graça de sentido" (ELIOT, 2018, p. 229). E no início da parte $V$ de "Burnt Norton", "somente pela forma, padrão,

É que música ou palavra calam

Fundo na imobilidade, como vaso chinês imóvel Perpetuamente move-se inamovivel (ELIOT, 2018, p. 235).

O poeta segue, e coloca o som de um violino, "enquanto dura a nota", como um potencial exemplo de coexistência, algo que sozinho não nos entrega esse eterno presente, mas é parte desse anseio:

Não como o violino, enquanto dura a nota,

Não isso apenas, mas coexistência,

Ou digamos que o fim precede o princípio,

E que fim e principio estiveram sempre lá

Antes do princípio e depois do fim (ELIOT, 2018, p. 235).

A forma e o padrão fazem com que a música se torne inaudita - música e palavra -, e o exemplo que ele dá em relação ao vaso chinês ilustra essa imagem de algo solene e silencioso, mas que, em si, traz a mobilidade na sua imobilidade.

Em seguida, em "East Coker" (p. 239), depois que repete o verso "Em meu principio está meu fim" nas duas primeiras estrofes - aquilo que Thomas Rees chama de "Tema Dominante" do poema (REES, 1969, p. 64) -, há um tema subdominante que podemos chamar de "a festa dos mortos".

9 "É uma grande e fina arte, seu efeito na natureza mais interior do homem é poderoso, e completamente e profundamente entendido por ele no seu eu mais interior como uma linguagem universal, cuja distinção atravessa até mesmo a própria percepção do mundo [...]. Nós precisamos atribuir à música uma significação muito mais séria e profunda e que se refira à parte mais interior do mundo e de nós próprios." 
O trecho diz o seguinte: "Se não se aproximar demais", passando uma ideia de que se nos aproximarmos muito a cena pode desaparecer, "você pode ouvir a música / Da fraca flauta e de um tambor pequeno" (ELIOT, 2018, p. 239).

A música parece tocar em um sonho, ou em uma outra vida. Ela só pode ser ouvida se você não se aproximar demais (Eliot repete essa frase, reforçando o seu ponto ao leitor). É interessante lembrar aqui da dança da morte no final do filme de Ingmar Bergman, O Sétimo Selo (1957).

Nela, os mortos parecem não se dar conta da sua situação e dançam de mãos dadas uma música que não soa, e que apenas um dos personagens, fora dessa dança, vê, e que, mesmo assim, parece uma ilusão. Talvez ele não tenha se aproximado demais, e por isso pôde ver e ouvir o não visto e o não ouvido. No final da parte II de "East Coker", "A dança some inteira sob o morro" (ELIOT, 2018, p. 245), da mesma forma que no filme de Bergman.

A música que toca durante a dança no ponto imóvel é, ao final de "Dry Salvages", "[...] música ouvida tão a fundo / Que nem mais se escuta, mas você é a música / Enquanto dura a música [...]" (ELIOT, 2018, p. 273). Novamente temos aqui a música inaudita, o inesperado "momento, momento dentro e fora do tempo", como dizem alguns versos acima. Ou seja, para tentar explicar melhor o que é esse momento, o poeta recorre, mais uma vez, à música. Esta não escutada porque ouvida naquilo que Jean-Luc Nancy chama de escuta (2013), e que, em suma, significa um estado em que o individuo entra em ressonância com o entorno e encontra um sentido de pertencimento universal.

É claro que tal conceito é abstrato, mas funciona aqui para complementar o que Eliot busca ao longo dos Quartetos. Não é à toa que Nancy coloca a música como o momento em que "som e o sentido igualmente se propõem à auscultação" (NANCY, 2013, p. 163), a música que, segundo Eliot, "nem mais se escuta". O indivíduo à escuta "é a música / Enquanto dura a música" (ELIOT, 2018, p. 273).

E, voltando a citar "Burnt Norton", esse estado a que o individuo aspira é atemporal e não localizável no tempo, ainda mais se pensarmos em um tempo relativo, e não absoluto:
Posso apenas dizer, lá estivemos: mas não posso dizer onde.

E não posso dizer por quanto, pois é localizar no tempo.

Internamente livre do desejo prático,

[...] luz branca fixa e móvel (ELIOT, 2018, p. 225).

Assim, a música atua aqui como um ideal buscado para tentar exemplificar aquilo que Eliot entende por eterno presente.

A última parte dos Quartetos, "Little Gidding", representa o ápice da espiritualidade, quando fogo e rosa se unem. É como se nesse estado ideal, nessa "condição de completa simplicidade" (ELIOT, 2018, p. 295), estivesse tocando uma música inaudita - e, por isso, mais doce, como disse Keats -, ouvida a fundo no ponto fixo em que a dança acontece.

\section{Conclusão}

Nos Quartetos, o autor persegue um ideal ao longo dos versos. E, se pensarmos na espécie de redenção a que ele se refere - o ápice da busca atingido, como aparece em "Little Gidding" -, a noção de tempo proposta pela teoria da relatividade de Einstein mostra-se aqui como um importante ângulo para se pensar a questão. A ideia de que espaço e tempo estão interligados, e que o tempo é, em si, uma grandeza relativa, atua como uma "evidência científica" para aquilo que Eliot propõe nos Quatro Quartetos.

A epifania, para o poeta, seria talvez o momento em que, vivendo inevitavelmente no presente, podemos entrar e estar em sinergia com o tempo passado e o futuro. Dessa forma, o tempo e a nossa mortalidade estariam suspensos e teriamos a compreensão de que a morte e a vida são a mesma coisa - "em meu princípio está meu fim" (ELIOT, 2018, p. 239). A circularidade da vida é a circularidade do tempo, e olhar uma estrela, como disse Stephen Hawking, a partir da teoria de Einstein, é presenciar essa união.

A música é, para Eliot, um modo de chegar a esse estado de epifania, por mais efêmero que ele possa ser. E uma explicação para esse fato pode estar no artigo já mencionado anteriormente, "Music and the analogue of feeling: notes on Eliot and Beethoven", de Harvey Gross, o teórico diz: 
In listening to the Pastoral Symphony, we do not experience nature; nor do we necessarily form mental images of the walk in the country, the flowing brook or the shepherd playing on his flute. The bucolic opening theme of the symphony is bucolic only if we want to think it so. [...] Music requires no action on the listener's part. The Marcia Funebre of the Eroica tells of grief and consolation, but we need console no mourners nor show any sympathy. We apprehend grief in its deepest and most painful aspects; we know more about grief than language could possibly communicate (GROSS, 1959, p. 280-281). ${ }^{109}$

Nós podemos nos perguntar aqui se o fato da música significar tanto assim - ao menos na visão de Harvey Gross - faz que com que ela não tenha nenhum significado. Em outras palavras, se o estado da música "ouvida tão a fundo que nem mais se escuta" é tão subjetivo e inapreensivel que se torna o "alvo que jamais será atingido; / Que só seguimos invictos / Porque seguimos lutando" (ELIOT, 2018, p. 273)?

E, nesse momento subjetivo e inapreensivel, lembremos aqui de outro trecho de Eliot (2018, p. 225): "mas com que propósito perturbar a poeira num prato de folhas de rosas"?

Independente de tudo isso, ele buscou entender, descrever e prescrever esse estado nos seus Quartetos. E aliando o poema à teoria sobre o tempo proposta por Einstein, temos o gérmen de uma discussão interessante, e que sem dúvida faz com que possamos analisar a obra de T. S. Eliot sob um ângulo inusitado e diferente.

\section{REFERÊNCIAS}

ELIOT, T. S. T. S. Eliot - Poemas. Tradução: Caetano W. Galindo. São Paulo: Companhia das Letras, 2018.

FAIRCHILD, Terry. Time, Eternity, and Immortality in T. S. Eliot's Four Quartets. Modern Science And Vedic Science, Fairfield, v. 9, n. 1, p. 50-101, abr. 1999. Disponivel em: https://www.mum.edu/pdf_msvs/vog/fairchild.pdf. Acesso em: 24 jul. 2019.

GROSS, Harvey. Music And The Analogue Of Feeling: Notes On Eliot And Beethoven. The Centennial Review of Arts \& Science, [s. l.], v. 3, n. 3, p. 269-288, 1959. Disponivel em: Www.jstor.org/stable/23737576. Acesso em: 24 jul. 2019.
KEATS, John. Ode Sobre a Melancolia e Outros Poemas. Organização e Tradução: Péricles Eugênio da Silva Ramos. São Paulo: Hedra, 2010. 154 p.

NANCY, Jean-luc. À escuta (parte I). Tradução: Carlos Eduardo Schmidt Capela e Vinícius Nicastro Honesko. Outra Travessia, [s. l.], v. 1, n. 15, p.1 59-172, 3 out. 2013. Disponivel em: https://periodicos.ufsc.br/index.php/ Outra/article/view/2176-8552.2013n15p159. Acesso em: 24 jul. 2019. 10.5007/2176-8552.2013n15p159.

REES, Thomas R. The Orchestration of Meaning in T. S. Eliot's Four Quartets. The Journal of Aesthetics and Art Criticism, v. 28, n. 1, p. 63-69, 1969. Disponivel em: http:// www.jstor.org/stable/428910. Acesso em: Acesso em: 24 jul. 2019. https://doi.org/10.2307/428910.

SCHOPENHAUER, Arthur. The World as Will and Representation. New York: Dover Publications, 1966. 1 V.

\section{João Felipe Gremski}

Mestre em Estudos Literários pela Universidade Federal do Paraná (UFPR). Atualmente faz doutorado pela mesma instituição com o projeto de tese intitulado "A Literatura como Formadora da Visão de Mundo do Músico Gustav Mahler" (título provisório). Lançou recentemente, em 2019, um livro de poemas intitulado "Peso Morto" pela Editora Circuito.

\footnotetext{
10 "Ao ouvirmos a sinfonia Pastoral, nós não temos a experiência da natureza e nem formamos, necessariamente, imagens mentais de uma caminhada no campo, o rio correndo ou o pastor tocando a sua flauta. O bucólico tema de abertura da sinfonia é bucólico apenas se nós quisermos que ele seja. [...] A música não requer ação por parte do ouvinte. A Marcia Funebre da [sinfonia] Eroica fala de luto e consolação, mas nós não precisamos consolar ninguém em luto e nem demonstrar nenhuma compaixão. Nós apreendemos o luto nos aspectos mais profundos e dolorosos; nós sabemos mais sobre o luto do que a linguagem pode querer comunicar".
} 